\title{
Orbital Lifetime (2008-2017) Radiometric Calibration and Evaluation of the HJ-1B IRS Thermal Infrared Band
}

\author{
Wanyue Liu ${ }^{1,2}$, Jiaguo $\mathrm{Li}^{2, *} \mathbb{0}$, Qijin Han ${ }^{3}$, $\mathrm{Li} \mathrm{Zhu}^{4}{ }^{4}$, Hongyan Yang ${ }^{4}$ and Qiuming Cheng ${ }^{1,5}$ \\ 1 School of Earth Sciences and Resources, China University of Geosciences, Beijing 100083, China; \\ 3001190109@cugb.edu.cn (W.L.); qiuming.cheng@iugs.org (Q.C.) \\ 2 Aerospace Information Research Institute, Chinese Academy of Sciences, Beijing 100101, China \\ 3 China Center for Resource Satellite Data and Application, Beijing 100094, China; hanqijin@chinasiwei.com \\ 4 Ministry of Ecology and Environment Center for Satellite Application on Ecology and Environment, \\ Beijing 100094, China; zhu.li@mee.gov.cn (L.Z.); yanghy@secmep.cn (H.Y.) \\ 5 State Key Lab of Geological Processes and Mineral Resources, China University of Geosciences, \\ Beijing 100083, China \\ * Correspondence: lijg@radi.ac.cn; Tel.: +86-1861-840-3607
}

Received: 24 May 2020; Accepted: 21 July 2020; Published: 23 July 2020

check for updates

\begin{abstract}
The infrared sensor (IRS) is a payload on the HJ-1B satellite and includes a thermal infrared band (B08). In order to obtain radiometric calibration coefficients and evaluate annual change, this study performed an analysis covering its 10-year orbital lifetime (2008-2017). The cross-calibration of IRS B08 with MODIS was performed using near-simultaneous images over Lake Qinghai, China. The results reveal that the radiometric response of IRS B08 notably changed during its orbital lifetime from year-to-year. The offsets fluctuated more than the gain. The top-of-atmosphere (TOA) radiance obtained by calibration coefficients in this study was generally in agreement with those obtained by onboard calibrator, within an error range of $\pm 4.00 \%$ from 2008 to 2012 . The percent difference compared with field validation was within $1.63 \%$. The difference between IRS and MODIS radiance over field validation sites was within $\pm 5 \%$. Approximately a $1 \%$ difference occurred between the TOA temperature of IRS and MODIS. The radiometric response of IRS B08 continuously decreased from 2008 to 2013, whereas it fluctuated from 2014 to 2017. Moreover, the DN fluctuated more when the at-aperture radiance was low, although it was more stable at higher radiance.
\end{abstract}

Keywords: cross-calibration; HJ-1B/IRS; orbital lifetime; thermal infrared; evaluation

\section{Introduction}

Research utilizing derived thermal infrared data has become a hot topic in recent decades. The value of thermal data archives will continue to grow since they can be applied to many areas, such as the monitoring of evapotranspiration [1,2], the estimation of soil moisture [3], the detection of the geothermal system $[4,5]$ and mineral mapping $[6,7]$. In order to take proper advantage of thermal infrared data, a critical step is radiometric calibration, which converts observed digital numbers (DNs) to physical radiance quantities [8]. One of the virtual purposes of this process is to provide calibration coefficients to consistently convert DNs into top-of-atmosphere (TOA) radiances. The converted radiance that explicitly embodies the reflective or emissive properties from the terrestrial surface is usually taken as the most important preliminary input in quantitative applications.

In general, there are four main methods used to obtain calibration coefficients: preflight calibration, in-flight calibration, vicarious calibration and cross-calibration. Since the in-orbit environment differs from the simulated environment in the laboratory, post-flight calibration is required even if the preflight 
calibration is performed perfectly [9]. Meanwhile, in-flight calibration is heavily dependent upon the onboard calibration systems. Vicarious calibration requires a large amount of simultaneous data and its cost is usually high [10]. In addition, it cannot be used to calibrate historical data. Comparatively speaking, cross-calibration is a more flexible and economic way to obtain calibration coefficients, especially for historical data [11-15].

The HJ-1 constellation contains two optical satellites (HJ-1A and $\mathrm{HJ}-1 \mathrm{~B})$ and a radar satellite $(\mathrm{HJ}-1 \mathrm{C})$. It was launched on September 6, 2008, with the specific objective of obtaining data that could be used for environmental protection and disaster reduction in China. The life expectancy of IRS was only three years, but it has now provided records of the Earth's surface for more than a decade [16,17]. The payloads on the HJ-IB contain a 4-band charge-coupled device (CCD) and another 4-band infrared sensor (IRS), including a thermal infrared band (B08). The spectral range of IRS B08 is 10.5-12.5 $\mu \mathrm{m}$, and the spatial resolution is $300 \mathrm{~m}$. The IRS has a high temporal resolution (every four days) and its images are freely available to the public. The sea surface temperature (SST) [18] and land surface temperature (LST) [19,20] can be retrieved from the IRS B08. The retrieved SSTs from the IRS are within the acceptable range. The improved mono-window algorithm for retrieving LST established by Zhou et al. [19] is applicable and feasible in actual conditions when compared to MODIS LST products. Given these advantages, the data are more suitable for eco-environment monitoring in near real time than Landsat as well as assessment accuracy than MODIS. Examples include the detection of urban heat islands [21-24], the monitoring of abnormal thermal points [25,26], the mapping of urban land cover [27], the monitoring of water bodies [28]. Wong et al. [21] developed a novel algorithm to estimate anthropogenic heat fluxes using HJ-1B images. Their method can help in the understanding of the anthropogenic heat flux relationship with and formation of the urban heat islands effect. Wu et al. [24] utilized various biophysical indices, such as NDVI, landscape metrics, to test the performance of the HJ-1B thermal infrared band in the monitoring of urban heat islands. Their findings revealed the impacts of the spatial structure of land use on urban heat islands, which is helpful for improving the planning and management of the urban environment. A spatiotemporal model established by Lin et al. using HJ-1B/IRS images performed better for background brightness temperature prediction during the fire season when compared to the contextual algorithm. HJ-1B images can be used to improve the classification accuracies of detailed urban land-cover mapping [27]. However, those studies are mainly focused on the images before 2013, the images acquired after 2013 are not fully used due to the lack of radiometric calibration coefficients.

Since the launch of HJ-1 constellation, the instrument response of the thermal infrared band has changed over time [14,29]. In addition, it may be affected by various uncertainty factors, such as straylight [30,31]. Accordingly, its in-orbit radiometric characteristics have inevitably deviated from those designed in the pre-launch laboratory. Therefore, radiometric calibration and evaluation on an annual basis are required for utilization of the IRS data. The China Center for Resource Satellite Data and Application (CCRSDA) was responsible for updating the IRS radiometric calibration coefficients from 2008 to 2012. Regrettably, the CCRSDA ended this updating in 2013 due to the loss of on-board calibration ability, although the IRS continued its in-orbit function for the next five years through 2017. Here, in order to improve the accuracy and usefulness of the application of IRS images and to compensate for the lack of radiometric calibration coefficients, we performed cross-calibration of the IRS B08 with moderate-resolution imaging spectroradiometer (MODIS) B31 and B32 over 10 yearperiod (2008-2017). Furthermore, we also analyzed the instrument response variation over its entire orbital lifetime, with the expectation of discovering the detector's decay characteristics.

\section{Materials and Methods}

\subsection{Study Areas and Data Sources}

\subsubsection{Cross-Calibration Site}

Water is an ideal target for thermal infrared calibration, given its high emissivity and low surface temperature variation across large areas over short time spans. Lake Qinghai (Figure 1) located 
between $36^{\circ} 32^{\prime} \sim 37^{\circ} 15^{\prime} \mathrm{N}, 99^{\circ} 36^{\prime} \sim 100^{\circ} 16^{\prime} \mathrm{E}$, is the largest inland saltwater lake in China. It has an area of $4473 \mathrm{~km}^{2}$ and a maximum depth of $32.8 \mathrm{~m}$. The surface elevation is $3196 \mathrm{~m}$ above sea level, and the atmosphere above the site is typically dry and stable with low amounts of total water vapor content in the atmospheric column. The surface temperature is uniform, with a horizontal surface temperature gradient $<0.12{ }^{\circ} \mathrm{C}$. Hence, the water body is a natural infrared radiation target. According to Wan et al. [32,33], Lake Qinghai is one of the primary thermal infrared calibration fields in China, and is widely used in satellite in-orbit radiometric calibration.

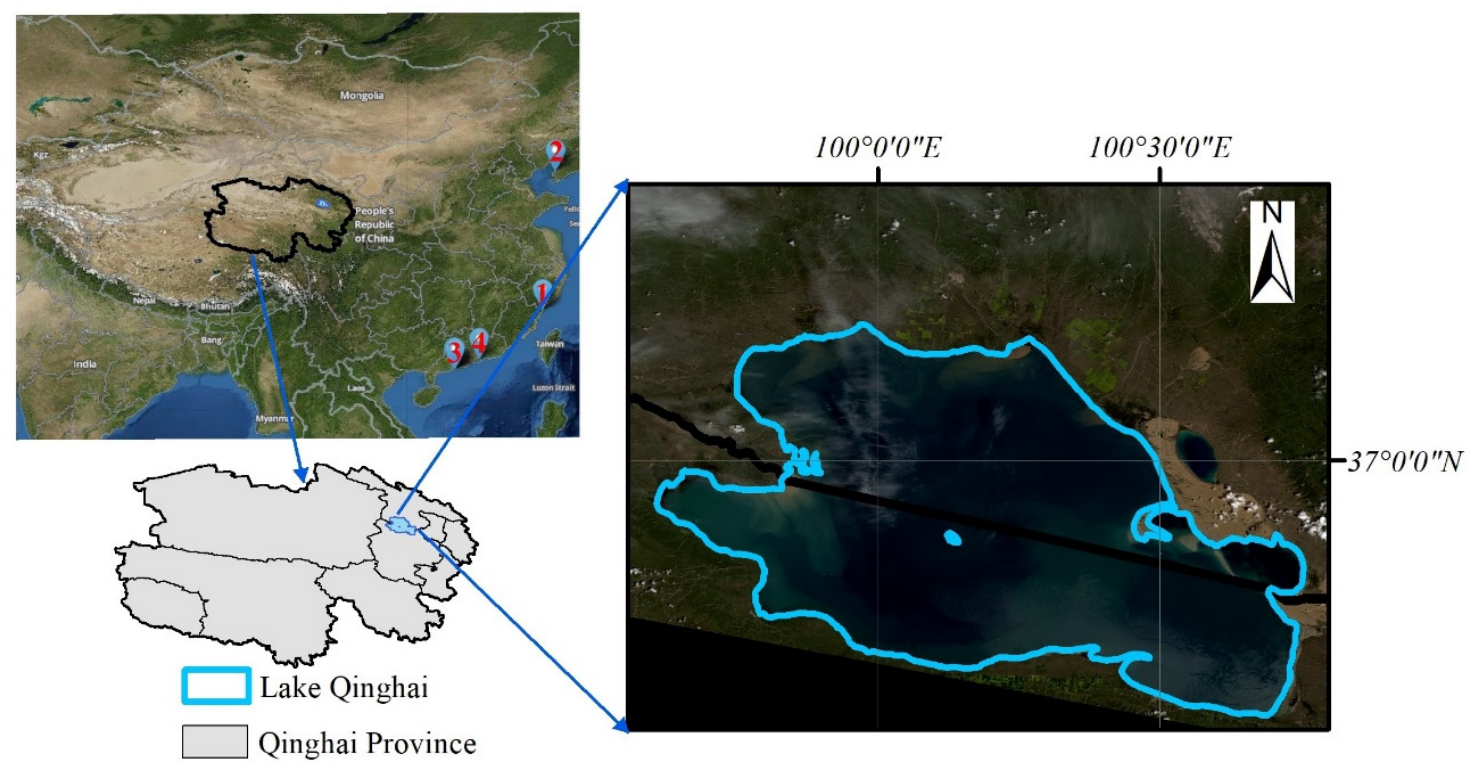

Figure 1. Relative location of Lake Qinghai, China. Red numbers in figure are field experiment sites.

\subsubsection{Reference Data}

The cross-calibration method requires relatively high calibration accuracy of the reference sensor. The MODIS is an important sensor on the Terra that observes the Earth's surface every 1-2 days. The MODIS instrument has 36 bands, and its thermal infrared (TIR) range is $3-15 \mu \mathrm{m}$. MODIS band $31(10.78-11.28 \mu \mathrm{m})$ and band $32(11.77-12.27 \mu \mathrm{m})$ overlapped with IRS band $08(10.50-12.50 \mu \mathrm{m})$; a comparison of their channel response functions is presented in Figure 2. In addition, the MODIS TIR bands are perfectly calibrated through the onboard blackbody, and the uncertainty of absolute radiometric accuracy for bands 31 and 32 is $2 \%[33,34]$. Since both are morning satellites the pass time difference between the Terra and the HJ-1B over Lake Qinghai is about $1 \mathrm{~h}$-and sometimes only a few minutes. Therefore, this study selected MODIS B31 and B32 as the reference channels for the IRS B08 cross-calibration.

Table 1 compares the thermal band features of both instruments.

Table 1. Comparison of selected thermal band features of the infrared sensor (IRS) and moderate-resolution imaging spectroradiometer (MODIS).

\begin{tabular}{ccccc}
\hline & Band Pass $(\boldsymbol{\mu m})$ & Spatial Resolution $(\mathrm{m})$ & Signal Quantization Levels $(\mathbf{b i t s})$ & NE $\Delta$ T $(\mathrm{K})$ \\
\hline IRS B08 & $10.50-12.50$ & 300 & 10 & 0.38 \\
MODIS B31 & $10.78-11.28$ & 1000 & 12 & 0.05 \\
MODIS B32 & $11.77-12.27$ & 1000 & 12 & 0.05 \\
\hline
\end{tabular}




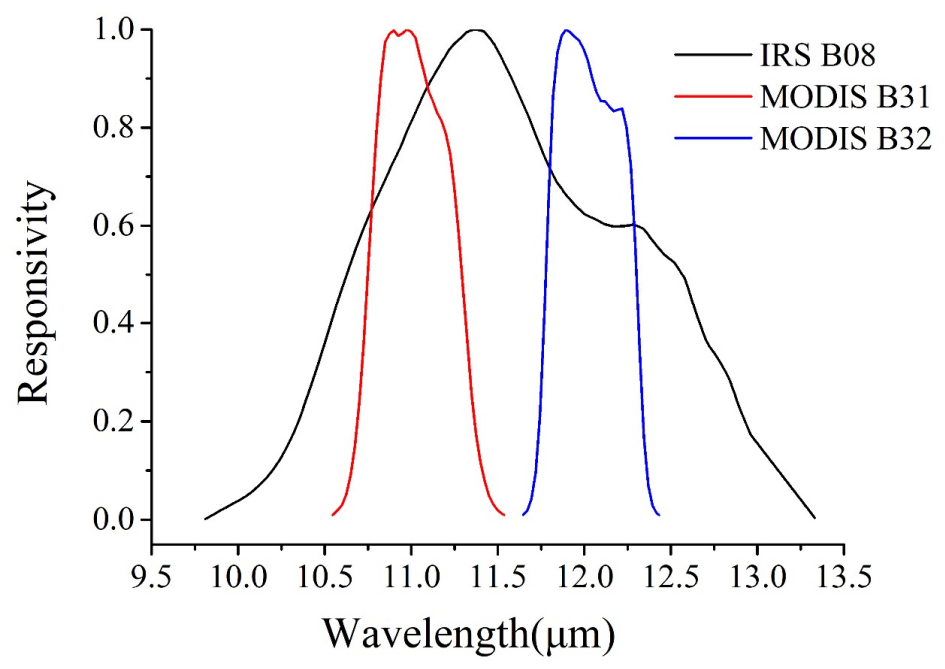

Figure 2. Comparison of channel response functions between Terra/MODIS B31 and B32 and the HJ-1B/IRS B08.

\subsubsection{Image Pairs Matching and Statistics}

Near-simultaneous IRS and MODIS images over Lake Qinghai were selected and matched as one-to-one experimental data pairs. Excluding images dominated by cloud or ice, 208 image pairs were chosen. Based on the accuracy distribution characteristics of the twin-channel difference model used in this study (introduced in the section below), 56 pairs with MODIS-view zenith angles $>50^{\circ}$ were discarded. The remaining 152 pairs were then used to perform the radiometric calibration. The images pairs were further subdivided into three groups based on their corresponding MODIS-view zenith angle, i.e., within $30^{\circ}$, within $40^{\circ}$ and within $50^{\circ}$. The annual effective data volumes are graphed in Figure $3 \mathrm{a}$ and the distribution of the MODIS-view zenith angle is plotted in Figure $3 \mathrm{~b}$.

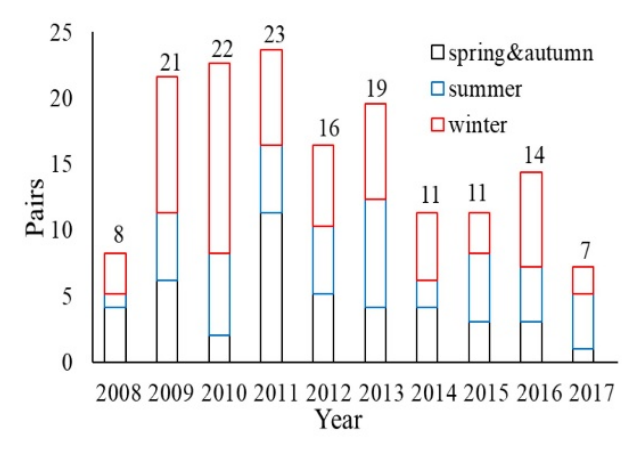

(a)

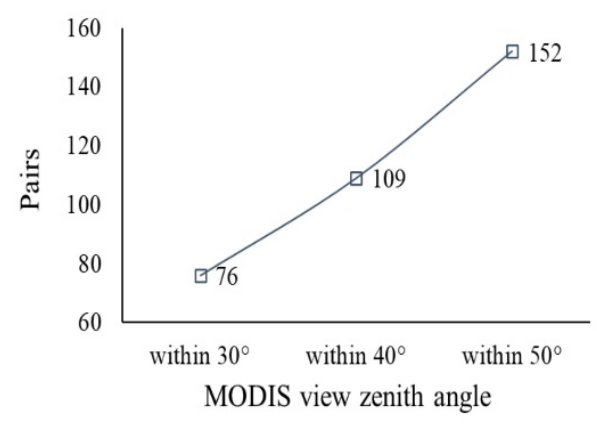

(b)

Figure 3. Effective matched-image pairs and statistics. (a) The annual effective data volumes; (b) image pairs corresponding with MODIS-view zenith angle.

\subsection{Methods}

\subsubsection{Image Preprocessing}

Image preprocessing includes fine geometric correction and resampling. The Landsat thematic mapper (TM) image orthorectification method has been successfully employed. Therefore, the IRS and MODIS images were geometrically corrected based on the fine geometric correction data of the Landsat TM (LT05_L1TP_133034_20070822). Since the spatial resolution of IRS B08 is $300 \mathrm{~m}$ but are $1 \mathrm{~km}$ for MODIS B31 and B32 bands, IRS B08 data were resampled to MODIS $1 \mathrm{~km}$ resolution using cubic convolution. 
A uniform and stable subarea on the lake is the preferable region of interest (ROI) for performing cross-calibration. During the selection of the ROI, the lake surface was gridded into approximate $20 \mathrm{~km} \times 20 \mathrm{~km}$ squares [15], as illustrated in Figure 4. The squares containing both water and land were discarded in order to ensure feature uniformity in the target area. Each square labeled with row and column numbers in Figure 4 was iterated in order to mask and extract the radiance from MODIS B31 and B32, after which the radiance variance was calculated for each. The blue grid $(6,4)$ in Figure 4 corresponds to the smallest variance, indicating that the average thermal radiative characteristics in this grid are more uniform and stable than those in other grids. Therefore, this grid square was selected as the final ROI used to perform radiometric cross-calibration in this study.

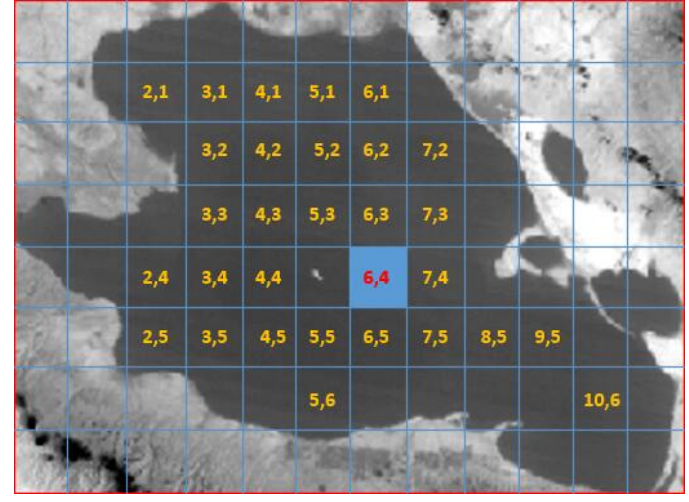

(a)

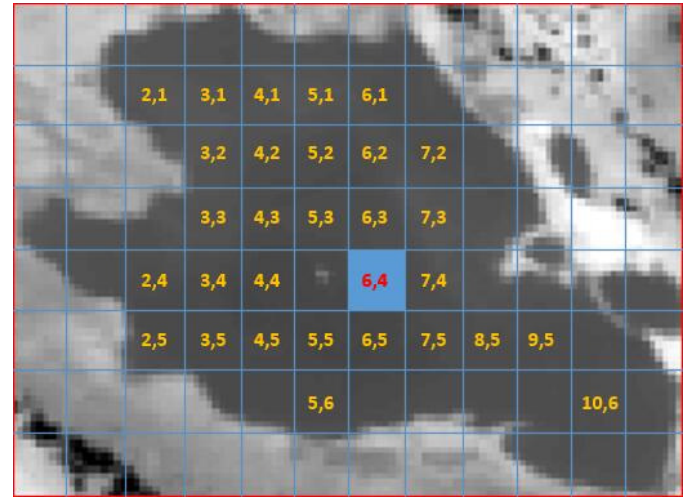

(b)

Figure 4. The most uniform and stable grid square of (a) IRS and (b) MODIS. The final region of interest (ROI) is depicted as a blue grid square in both images.

\subsubsection{TOA Radiance Calibration and Coefficients Regression}

The twin-channel difference model, which is a simplified physical model, was established based on radiative transfer model [16]. This model can avoid the effects of atmospheric temperature and density on the calibration process without additional observation parameters and is an ideal high-frequency and high-precision calibration algorithm for in-orbit sensors. Therefore, it was applied here to cross calibrate the IRS B08 with the MODIS B31 and B32.

The model is expressed by different combination of the TOA temperature of reference channels, as:

$$
\mathrm{T}_{\mathrm{H} 08}=\mathrm{a}_{1}+\mathrm{a}_{2} \cdot \mathrm{T}_{\mathrm{M} 31}+\mathrm{a}_{3} \cdot\left(\mathrm{T}_{\mathrm{M} 32}-\mathrm{T}_{\mathrm{M} 31}\right),
$$

where $\mathrm{T}_{\mathrm{H} 08}$ is the TOA temperature of IRS B08 and $\mathrm{T}_{\mathrm{M} 31}, \mathrm{~T}_{\mathrm{M} 32}$ are the TOA temperatures of MODIS B31, B32, respectively. The coefficients $\mathrm{a}_{1}, \mathrm{a}_{2}, \mathrm{a}_{3}$ can be obtained from the cross coefficients' lookup table with corresponding observed geometric conditions.

Figure 5 illustrates the entire process for deducing radiometric coefficients via cross-calibration. The four main steps are described below.

1. Obtain the DN of IRS B08, the radiance of MODIS B31 and B32 and the view zenith angles of ROI area from near-simultaneous image pairs;

2. Convert the TOA radiance of MODIS B31, B32 into TOA temperature according to "temperatureradiance" lookup table and obtain cross coefficients, $\mathrm{a}_{\mathrm{i}}$, according to "cross coefficient" lookup table;

3. Calculate the TOA temperature of IRS B08 using Equation (1) and convert to TOA radiance through the inverse of the Planck function or the "temperature-radiance" lookup table.

4. Perform coefficients regression. The data obtained from the above process (DN and TOA radiance of IRS B08) were regressed using a linear equation as:

$$
\mathrm{L}=\frac{\mathrm{DN}-\mathrm{b}}{\mathrm{g}}
$$


where $\mathrm{DN}$ is the digital number, $\mathrm{L}$ is TOA radiance, and $\mathrm{b}$ and $\mathrm{g}$ are the radiometric calibration coefficients of the expected offset and gain, respectively. The unit of $g$ is $W^{-1} \cdot \mathrm{m}^{2} \cdot \mathrm{sr} \cdot \mu \mathrm{m}$, and $\mathrm{b}$ is unitless.

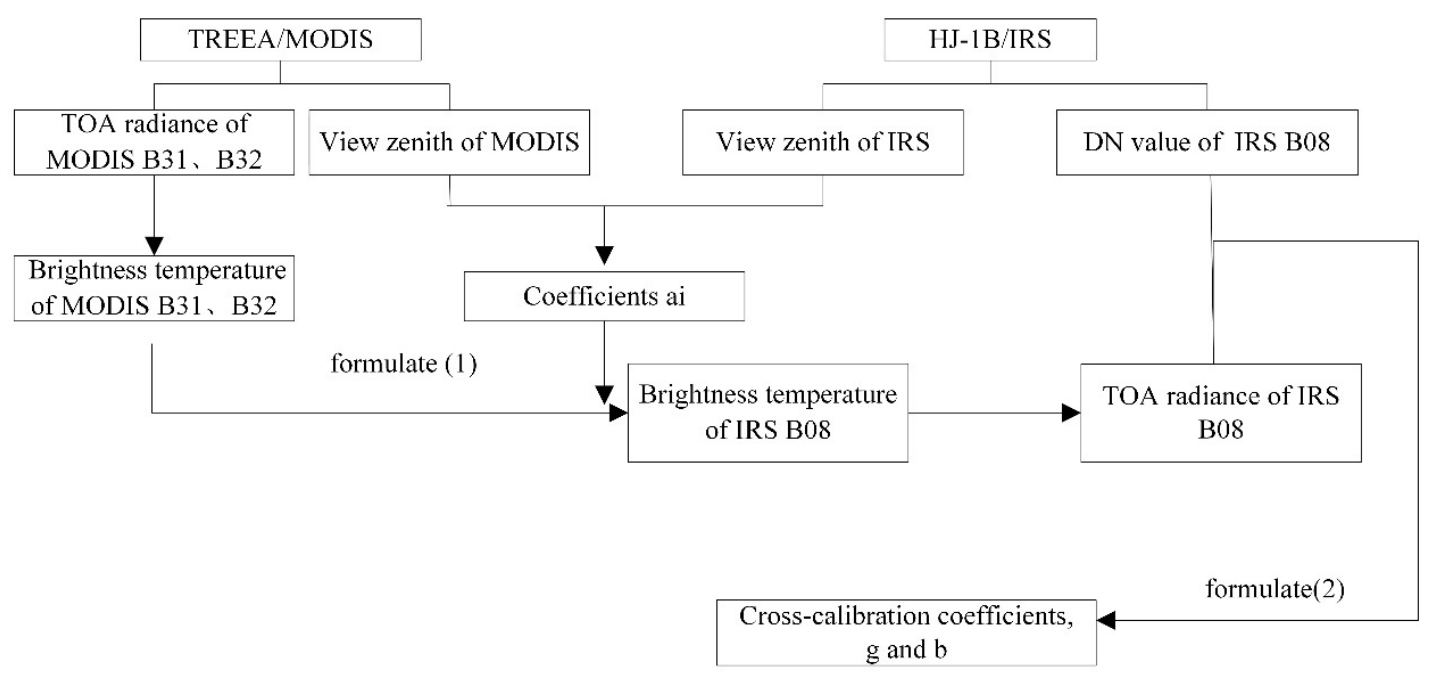

Figure 5. Flow chart of cross-calibration by twin-channel difference model.

\subsubsection{Field Experiment}

The field validation techniques estimated the TOA radiance over a selected test site. Next, the simulated radiance was convolved with the relative channel spectral response function to obtain the predicted radiance at sensor. Finally, the predicted radiance at sensor was compared with the measured radiance. The TOA radiance values were simulated with the help of the radiation propagation code MODTRAN [35] using field measurements as inputs. Measured radiance was tested with a Cimel CE312 radiometer, which was accurately calibrated by a highly accurate field portable blackbody (Mikron M340) before and after the satellite overpass. Water was used as the target. The experiment was conducted concurrent with the satellite transit time.

The temperature-based method for radiation propagation to the sensor can be expressed as:

$$
\mathrm{L}_{\mathrm{TOA}}=\tau \cdot \frac{\int\left[\varepsilon(\lambda) \mathrm{B}(\lambda, \mathrm{T})+(1-\varepsilon(\lambda)) \mathrm{L}^{\downarrow}(\lambda)\right] \mathrm{R}(\lambda) \mathrm{d} \lambda}{\int \mathrm{R}(\lambda) \mathrm{d} \lambda}+\mathrm{L}^{\uparrow}=\tau \mathrm{L}_{\mathrm{obs}}+\mathrm{L}^{\uparrow}
$$

where $\mathrm{L}_{\mathrm{TOA}}$ is the TOA radiance, $\tau$ is the atmospheric transmittance from ground to sensor, $\varepsilon(\lambda)$ is the spectral emissivity of the observed target, $\mathrm{B}(\lambda, \mathrm{T})$ is the Planck function associated with a target at temperature $T, L^{\downarrow}(\lambda)$ is the spectral downwelling radiance, $L^{\uparrow}(\lambda)$ is the channel upwelling radiance, $R(\lambda)$ is the relative channel spectral response function of the sensor (IRS in this study) and $L_{o b s}$ is the channel radiance assuming the sensor was located on the ground.

In the radiance-based method, $\mathrm{L}_{\mathrm{obs}}$ is calculated using Equation (4):

$$
\mathrm{L}_{\mathrm{obs}}=\frac{\varepsilon_{\mathrm{obs}} \mathrm{B}\left(\lambda_{\mathrm{obs}}, \mathrm{T}\right)+\left(1-\varepsilon_{\mathrm{obs}}\right) \mathrm{L}^{\downarrow}}{\varepsilon_{\mathrm{M}} \mathrm{B}\left(\lambda_{\mathrm{M}}, \mathrm{T}\right)+\left(1-\varepsilon_{\mathrm{M}}\right) \mathrm{L}_{\mathrm{M}}^{\downarrow}} \cdot \mathrm{L}_{\mathrm{M}}
$$

where $\mathrm{M}$ is the parameter that corresponds to the ground instrument (the Cimel CE312 in this study).

The atmospheric profile data used by MODTRAN to simulate $\tau, \mathrm{L}^{\uparrow}$ and $\mathrm{L}^{\downarrow}$ were from atmospheric sounding balloons.

The field experiment sites used for this study are listed in Table 2. They are distributed in the southeast coastal area of China, from temperate to subtropical. The tested water temperature ranged from 280 to $295 \mathrm{~K}$. 
Table 2. Field experiment information $\left({ }^{*}\right.$ Numbers correspond to Figure 1$)$.

\begin{tabular}{ccccc}
\hline Number $^{*}$ & Date & Site & Longitude & Latitude \\
\hline 1 & 26 October 2013 & Ningde, China & $120.31^{\circ} \mathrm{E}$ & $27.04^{\circ} \mathrm{N}$ \\
2 & 12 June 2014 & Hongyanhe, China & $121.46^{\circ} \mathrm{E}$ & $39.78^{\circ} \mathrm{N}$ \\
3 & 28 January 2015 & Yangjiang, China & $112.17^{\circ} \mathrm{E}$ & $21.42^{\circ} \mathrm{N}$ \\
4 & 14 October 2016 & Daya Bay, China & $114.32^{\circ} \mathrm{E}$ & $22.36^{\circ} \mathrm{N}$ \\
4 & 21 October 2017 & Daya Bay, China & $114.32^{\circ} \mathrm{E}$ & $22.36^{\circ} \mathrm{N}$ \\
\hline
\end{tabular}

\section{Results}

\subsection{Annual Calibration Coefficients}

The radiometric calibration coefficients of the IRS B08 from 2008 to 2017 obtained in this study are listed in Table 3, while, the official coefficients provided by the CCRSDA from 2008 to 2012 are listed in Table 3.

Table 3. Radiometric calibration coefficients of IRS B08 from 2008 to 2017.

\begin{tabular}{|c|c|c|c|c|c|}
\hline \multicolumn{4}{|c|}{ Cross-Calibration Coefficients } & \multicolumn{2}{|c|}{ Official Coefficients } \\
\hline Year & $\left(\mathbf{W}^{-1} \cdot \mathbf{m}^{2} \cdot \mathbf{s r} \cdot \mu \mathrm{m}\right)$ & b & $\mathbf{R}^{2}$ & $\frac{\mathrm{g}}{\left(\mathbf{W}^{-1} \cdot \mathbf{m}^{2} \cdot \mathbf{s r} \cdot \mu \mathrm{m}\right)}$ & b \\
\hline 2008 & 62.293 & -37.409 & 0.9781 & 61.472 & -44.598 \\
\hline 2009 & 61.460 & -28.509 & 0.9937 & 59.421 & -25.441 \\
\hline 2010 & 57.548 & 2.755 & 0.9951 & 60.713 & -25.441 \\
\hline 2011 & 53.896 & 31.557 & 0.9916 & 56.277 & 12.626 \\
\hline 2012 & 52.385 & 41.471 & 0.9817 & 47.744 & 70.185 \\
\hline 2013 & 51.964 & 46.128 & 0.9891 & & \\
\hline 2014 & 54.680 & 23.084 & 0.9753 & & \\
\hline 2015 & 53.619 & 36.294 & 0.9865 & & \\
\hline 2016 & 51.983 & 45.359 & 0.9913 & & \\
\hline 2017 & 53.084 & 39.602 & 0.9875 & & \\
\hline
\end{tabular}

Figure $6 \mathrm{a}, \mathrm{b}$ presents the numeric values and percent changes of gains and offsets from 2008 to 2017. The mean value of the gains was $55.176 \mathrm{~W}^{-1} \cdot \mathrm{m}^{2} \cdot \mathrm{sr} \cdot \mu \mathrm{m}$ and the percent changes were within $\pm 6.5 \%$. The fluctuations of the offsets were greater than those of the gains, however.

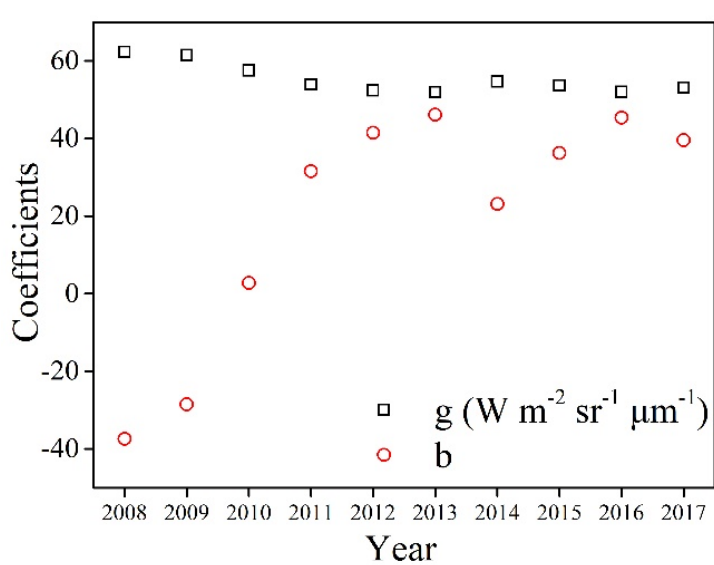

(a)

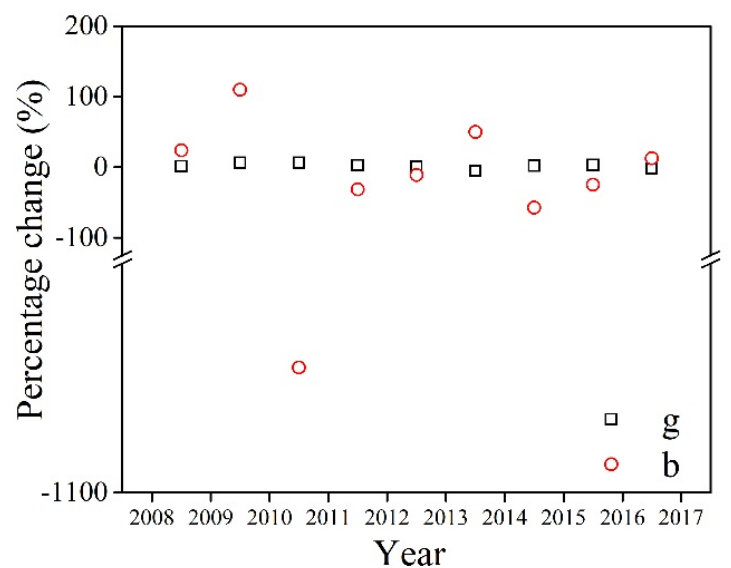

(b)

Figure 6. Gains and offsets in different years. (a) Numeric values; (b) percent changes. 


\subsection{Coefficients Validation}

\subsubsection{On-board Validation}

The official coefficients were obtained by on-board calibrators, which were used to validate the calibration results obtained in this study. The DNs of water in the images were approximately 400 , with most ranging from 300 to 500 . The radiance differences between the results obtained from the official coefficients and this study are shown in Figure 7. It can be seen that all the percent differences of radiance were within $\pm 4.00 \%$. The best fitting result exhibited a $0.16 \%$ difference, while the worst fitting result was $-3.64 \%$. These results indicate that the cross-calibration coefficients calculated in this study are reliable.

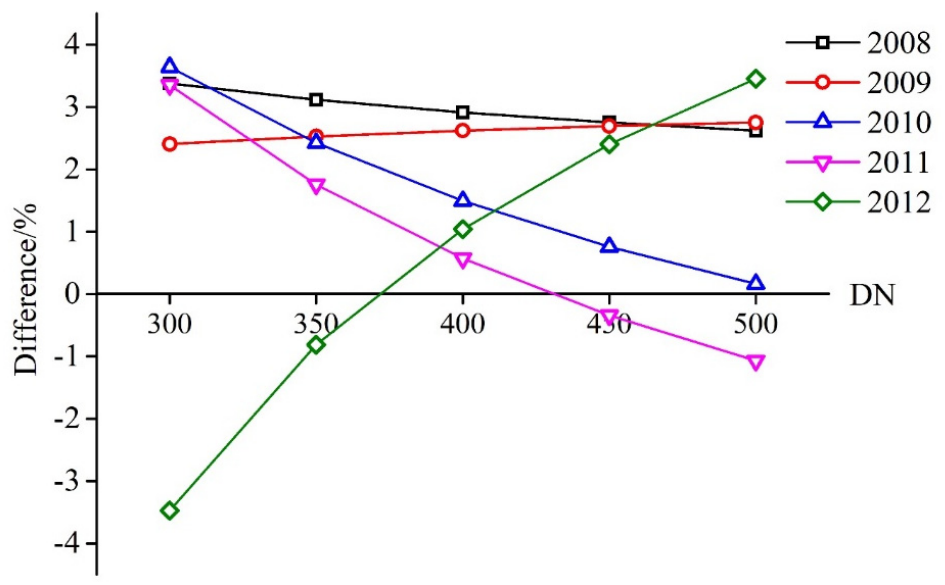

Figure 7. Radiance differences between official coefficients and this study.

\subsubsection{Vicarious Comparison}

Based on the field experiments, the TOA radiance was simulated with the help of MODTRAN. The comparison of the radiance calculated using the cross-calibration coefficients and the field campaign measurements is presented in Figure 8a. They were close to the 1:1 line and the total error was within $0.11 \mathrm{~W} \cdot \mathrm{m}^{-2} \cdot \mathrm{sr}^{-1} \cdot \mu \mathrm{m}^{-1}$, corresponding to approximately $1.0 \mathrm{~K}$ of TOA temperature. The percent difference was within $1.63 \%$. The image in 2014 was also calibrated using the calibration coefficients of the past few years. The radiance differences comparison between the cross-calibration and the field campaign is plotted in Figure 8b. These results indicated that not only the accuracy of the calibration coefficients in this study was reliable, but also the performance of the sensor changed with time.

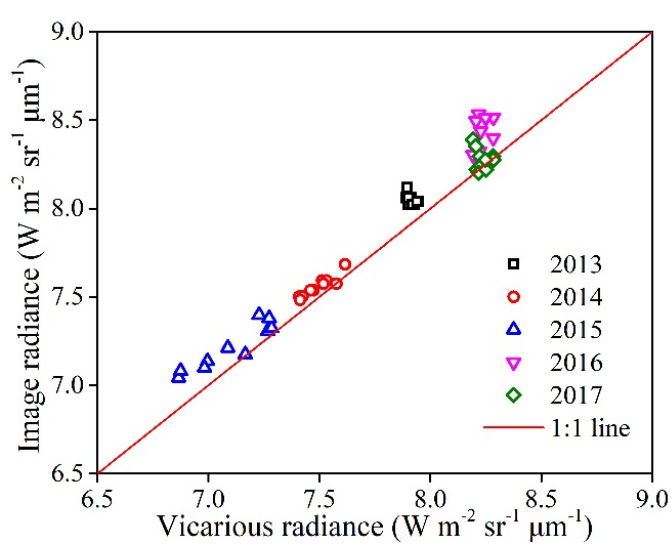

(a)

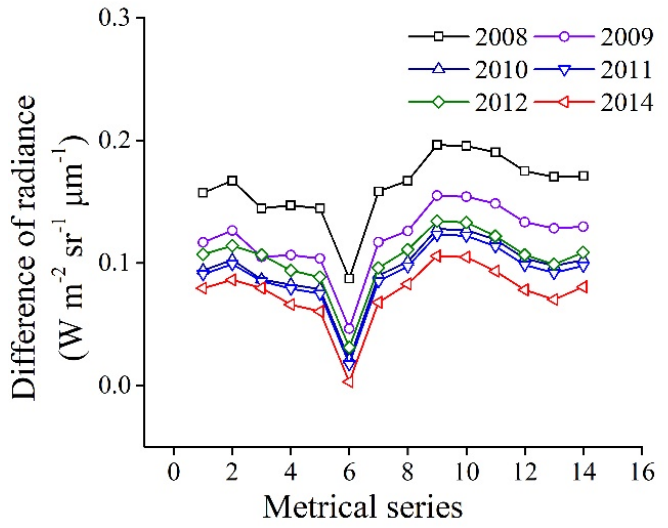

(b)

Figure 8. (a) Plot of radiance predicted at sensor versus measured vicarious radiance for the IRS; (b) difference of top-of-atmosphere (TOA) radiance by different calibration coefficients (2014). 


\subsubsection{Image Cross-Comparison}

The radiance obtained from images of the IRS B08 and the MODIS B31 and B32 over the field experiment sites was compared; the results from these comparisons are plotted in Figure 9. Each data point on the plots corresponds to a sampling points in the field experiments.

Figure 9a summarizes the radiance comparison results for the IRS B08 vs. MODIS B31. The data points do not lie precisely on the 1:1 line. In fact, all data points lie below the 1:1 line, indicating that IRS B08 was underestimating radiance in comparison to the MODIS B31. In the percent difference plots shown in Figure 9b, IRS B08 radiance estimates are as much as 5\% lower. Figure 9c summarizes the radiance comparison results for the IRS B08 vs. MODIS B32. The percent difference plots presented in Figure $9 \mathrm{~d}$ show that all data points lie above the zero line, indicating that the IRS B08 appears to estimate a $1 \%$ to $4 \%$ higher radiance than the MODIS B32.

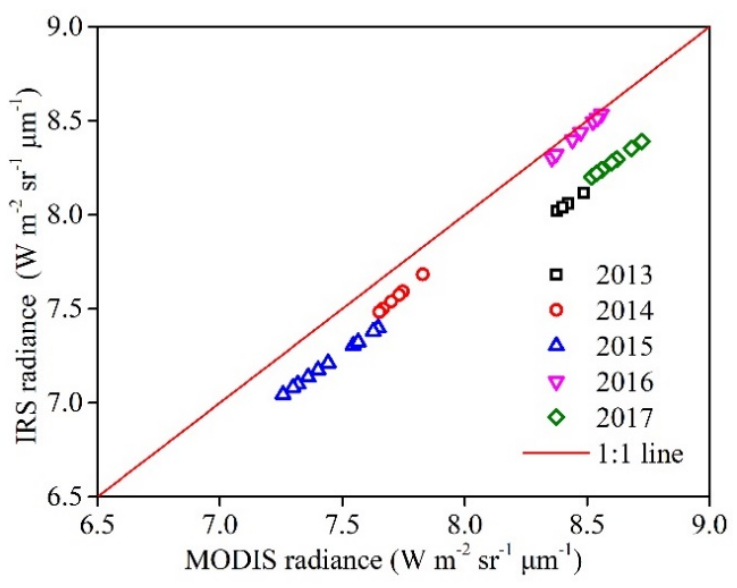

(a)

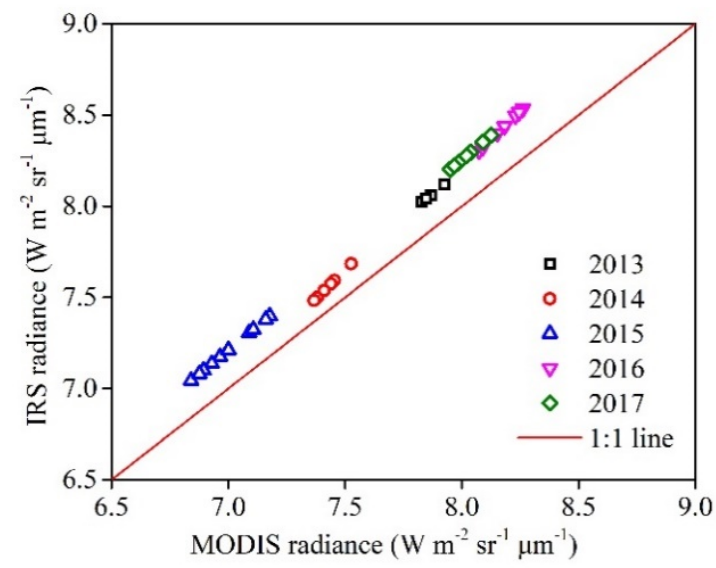

(c)

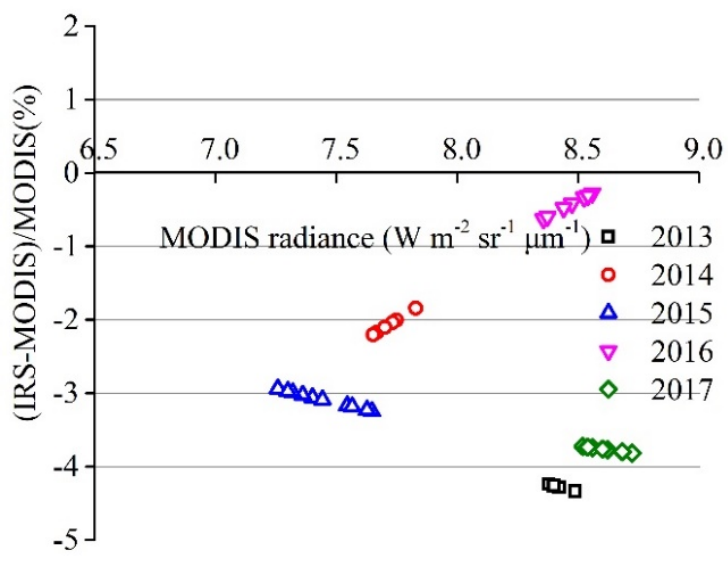

(b)

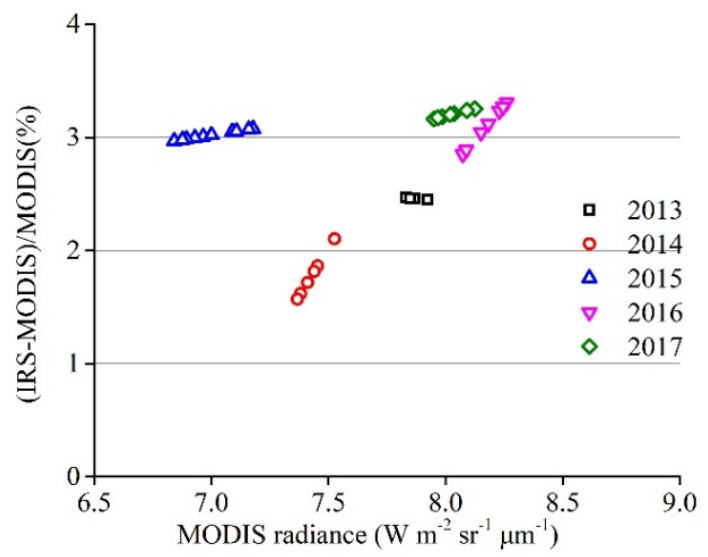

(d)

Figure 9. Comparison of radiance obtained from images of both IRS and MODIS sensors. IRS radiances were calculated using the calibration coefficients of this study. The MODIS radiances were obtained from MODIS L1B products. (a) IRS B08 vs. MODIS B31 radiance; (b) percent difference relative to MODIS B31; (c) IRS B08 vs. MODIS B32 radiance; (d) percent difference relative to MODIS B32.

\subsection{Relatively Low/Normal/High Radiance Variation}

According to the applicable conditions of the twin-channel difference model, coefficients $\mathrm{a}_{\mathrm{i}}$ could be applied to all images in which the TOA temperature ranged from 240 to $310 \mathrm{~K}$. When the temperature was $240 \mathrm{~K}$, the corresponding radiance was approximately $3.0 \mathrm{~W} \cdot \mathrm{m}^{-2} \cdot \mathrm{sr}^{-1} \cdot \mu \mathrm{m}^{-1}$. When the temperature was $310 \mathrm{~K}$, the corresponding radiance was approximately $10.0 \mathrm{~W} \cdot \mathrm{m}^{-2} \cdot \mathrm{sr}^{-1} \cdot \mu \mathrm{m}^{-1}$. The water DNs in the selected images were within 500 , corresponding to an at-aperture radiation of approximately 
$8.5 \mathrm{~W} \cdot \mathrm{m}^{-2} \cdot \mathrm{sr}^{-1} \cdot \mu \mathrm{m}^{-1}$. The corresponding $\mathrm{DN}$ values from low radiance $\left(3.0 \mathrm{~W} \cdot \mathrm{m}^{-2} \cdot \mathrm{sr}^{-1} \cdot \mu \mathrm{m}^{-1}\right)$ to high radiance $\left(10.0 \mathrm{~W} \cdot \mathrm{m}^{-2} \cdot \mathrm{sr}^{-1} \cdot \mu^{-1}\right)$ were computed using the cross-calibration coefficients obtained in this study, and the results are presented in Figure 10. These results indicate that the DN at low radiance increased slightly from 2008 to 2013 and fluctuated after that time. It was more stable at normal radiance, however. When the radiance was $8.0 \mathrm{~W} \cdot \mathrm{m}^{-2} \cdot \mathrm{sr}^{-1} \cdot \mu \mathrm{m}^{-1}$, the corresponding DN was a nearly horizontal line from 2008 to 2017. The DN at the high radiance range decreased slightly from 2008 to 2013 and fluctuated from 2014 to 2017.

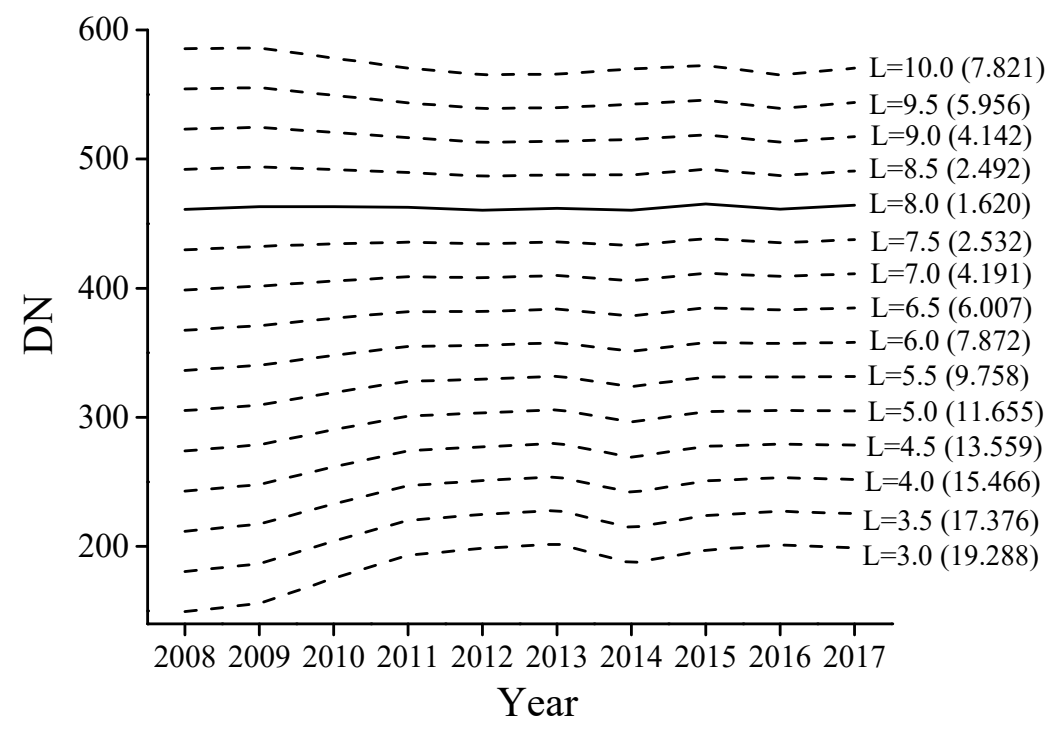

Figure 10. Response changes of IRS B08 at different radiance. " $\mathrm{L}$ " represents the radiance in unit of $\mathrm{W} \cdot \mathrm{m}^{-2} \cdot \mathrm{sr}^{-1} \cdot \mu \mathrm{m}^{-1}$ Numbers in brackets are the corresponding root mean square error of $\mathrm{DN}$ in different years. Digital number $(\mathrm{DN})$ values were calculated when the radiance range from 3.0 to $10.0 \mathrm{~W} \cdot \mathrm{m}^{-2} \cdot \mathrm{sr}^{-1} \cdot \mu \mathrm{m}^{-1}$.

\subsection{Channel Response Variation}

As shown in Figure $11 \mathrm{a}$, the TOA radiance range in the selected grids was $5.0-8.0 \mathrm{~W} \cdot \mathrm{m}^{-2} \cdot \mathrm{sr}^{-1} \cdot \mu \mathrm{m}^{-1}$. Therefore, we chose $5.0-8.0 \mathrm{~W} \cdot \mathrm{m}^{-2} \cdot \mathrm{sr}^{-1} \cdot \mu \mathrm{m}^{-1}$ as the input radiance interval to analyze the response of the sensor. The corresponding DNs were calculated with Equation (2) using the coefficients obtained in this study. The change in the DN range is presented in Figure $11 \mathrm{~b}$ and the attenuation percentages are shown in Figure 11c. The larger the DN range, the higher the sensitivity of the sensor. It can clearly be seen from Figure 11 that the sensitivity of the sensor decreased year-by-year from 2008 to 2013 , but fluctuated from 2014 to 2017.

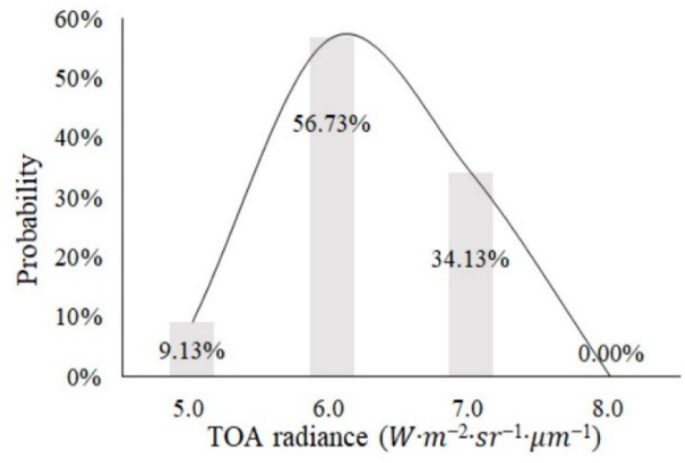

(a)

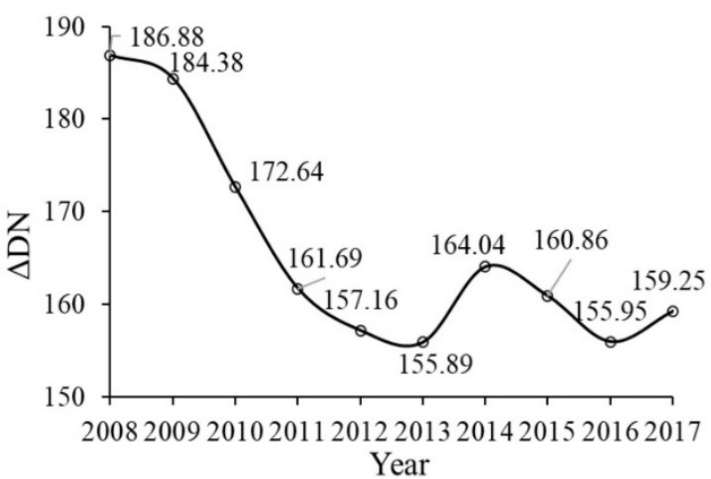

(b)

Figure 11. Cont. 


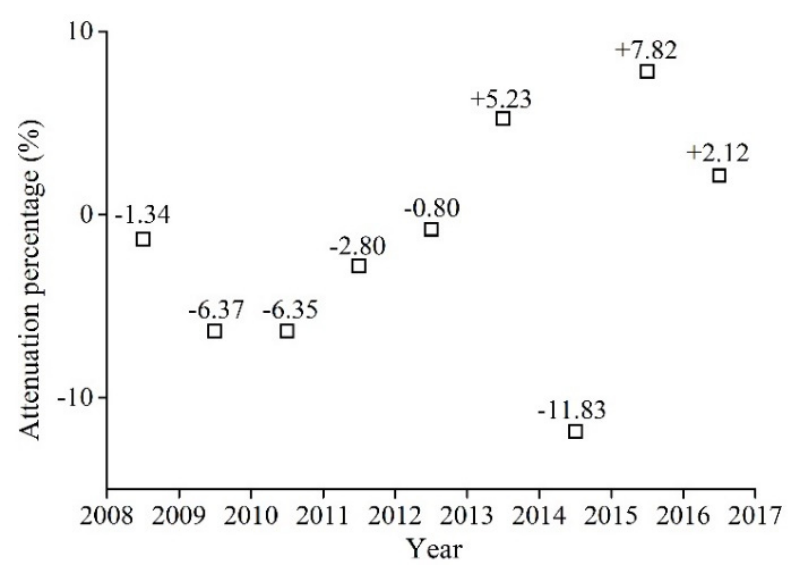

(c)

Figure 11. (a) TOA radiance in selected grid squares; (b) response characteristics of the IRS B08 during its lifetime. $\triangle \mathrm{DN}$ is the range of $\mathrm{DN}$ when the radiance range was $5.0-8.0 \mathrm{~W} \cdot \mathrm{m}^{-2} \cdot \mathrm{sr}^{-1} \cdot \mu \mathrm{m}^{-1}$, calculated according to the radiance calibration equation in this study; (c) percent attenuation from 2008 to 2017.

In summary, the radiometric response of the IRS B08 changed significantly during its orbital lifetime. A negative number indicates that the radiometric response was lower than the previous year. In other words, under the same radiance input interval, the DN range became smaller. The radiometric response exhibited a downward trend year-by-year from 2009 to 2013, with the largest decrease occurring in 2010. The radiometric response increased by $+5.23 \%$ in 2014 , however and fluctuated after that time.

\section{Discussion}

Hundreds of near-simultaneous images of Lake Qinghai were collected from 2008 to 2017. This provided a long-term sequence of images for the thermal infrared cross-calibration of the instrument. Temperature linearization between the IRS B08 and MODIS B31 was performed before cross-calibration, as shown in Figure 12a. They manifested a very close linear correlation. All data points lie very near the 1:1 line, indicating excellent temperature agreement between the two sensors. The percent difference plots (Figure $12 \mathrm{~b}$ ) suggest a difference of approximately $1 \%$ relative to IRS. Generally, in Figure 12c, the MODIS B31 displays a higher radiance than the IRS B08, while the MODIS B32 has a lower radiance than the IRS B08. Radiance and temperature distribution as a function of the MODIS and IRS lifetimes are shown in Figure 12d. In different years, each channel exhibited sinusoidal trends. Therefore, they were effective in further analysis.

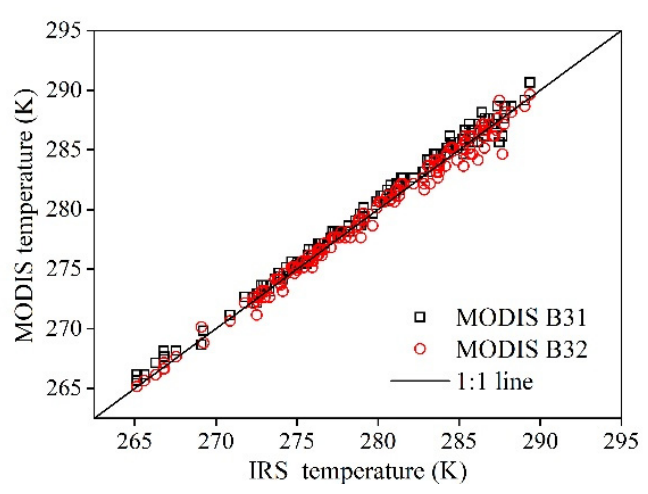

(a)

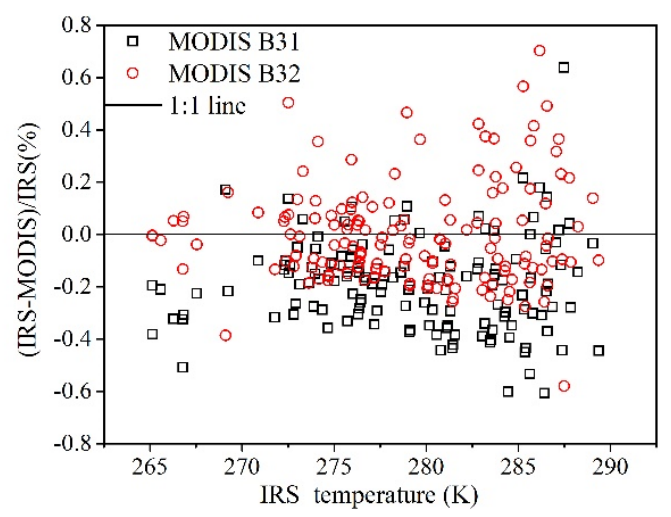

(b)

Figure 12. Cont. 


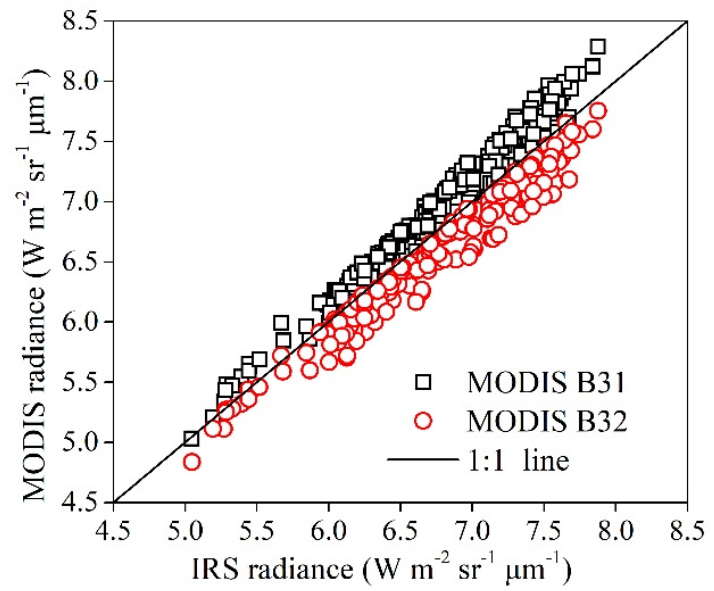

(c)

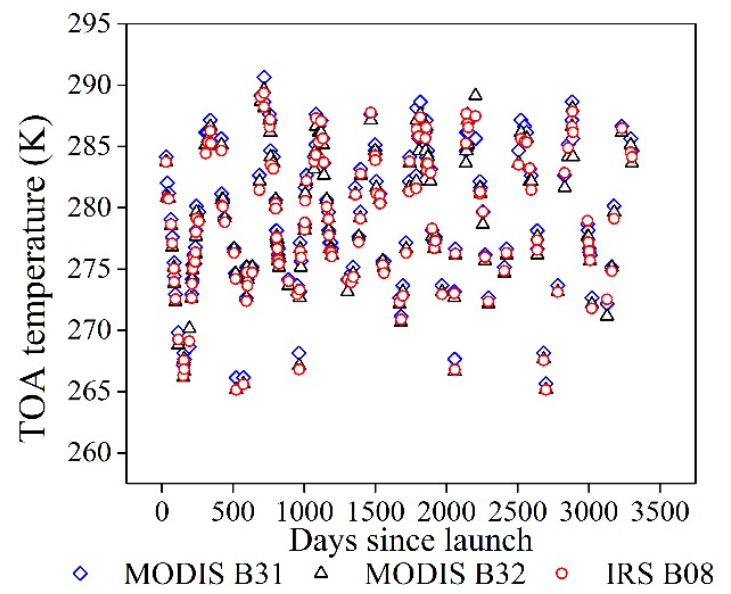

(d)

Figure 12. (a) Combined results of IRS and MODIS TOA temperature; (b) percent difference of TOA temperature between IRS and MODIS; (c) Combined results of IRS and MODIS TOA radiance; (d) TOA temperature temporal plot of MODIS and IRS.

In Section 2.1.3, we discarded image pairs with zenith angles $>50^{\circ}$ in the MODIS view. We selected images from 2011 in order to verify the validity of this choice, since 2011 had the largest number of effective image pairs in this study. As shown in Table 4, calibration accuracy is related to zenith angle. When images with a zenith angle $>50^{\circ}$ were included, the worst fitting result occurred. Therefore, it was effective to filter the images based on the zenith angle of the MODIS view.

Table 4. Fitting results of different MODIS-view zenith angles (2011).

\begin{tabular}{cccc}
\hline Zenith & $\mathbf{g}\left(\mathbf{W}^{-1} \cdot \mathbf{m}^{2} \cdot \mathbf{s r} \cdot \boldsymbol{\mu m}\right)$ & $\mathbf{b}$ & $\mathbf{R}^{\mathbf{2}}$ \\
\hline Within $30^{\circ}$ & 54.142 & 29.944 & 0.9949 \\
Within $40^{\circ}$ & 53.879 & 31.080 & 0.9938 \\
Within $50^{\circ}$ & 53.896 & 31.557 & 0.9916 \\
All angles & 52.329 & 41.789 & 0.9792 \\
\hline
\end{tabular}

As described in Section 3.3, the radiometric response of the IRS B08 at normal at-aperture radiance was relatively stable. Therefore, we regarded it as a fixed regression point $\left(\mathrm{L}=8.0 \mathrm{~W} \cdot \mathrm{m}^{-2} \cdot \mathrm{sr}^{-1} \cdot \mu \mathrm{m}^{-1}\right.$, $\mathrm{DN}=460$ ). Combined with another point obtained by cross-calibration from each image pair, the linear regression coefficients could be calculated. The gains and offsets are shown in Figure 13a,b. Both gains and offsets were more dispersed in summer than in other seasons. The average surface temperature of Lake Qinghai in summer is approximately $289.15 \mathrm{~K}$, and the highest temperature is $295.45 \mathrm{~K}$, corresponding to the normal radiance range discussed in Section 3.3. The radiation response in this range was stable, so the gap between the DN and TOA radiation derived from MODIS in summer and the fixed point was relatively small. Therefore, the slope of the fitted line was small. A slight change in slope will cause a large change in the reciprocal, which is the gain. As a result, gains in summer exhibited more volatility. Correspondingly, the offsets also fluctuated more in summer than in other seasons. However, gains and offsets in winter were more stable, due to the fact that DN changed more when the temperature (radiance) was low.

Overall, the cross-calibration method is a cost-effective technique that is particularly tailored for long-term historical data. The attenuation characteristics of the sensor during its lifetime can be further analyzed based on the calibration coefficients. The coefficients of the IRS B08, especially from 2013 to 2017, provides an accurate guarantee for the quantitative application of IRS data. These data can be further applied to waterline extraction, temperature retrieval and other areas. The research results have fully enhanced the value of the HJ-1B satellite data. 


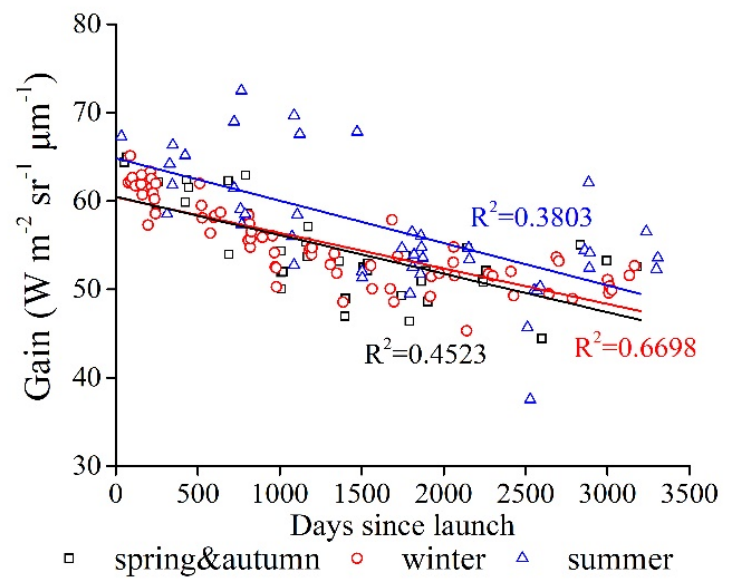

(a)

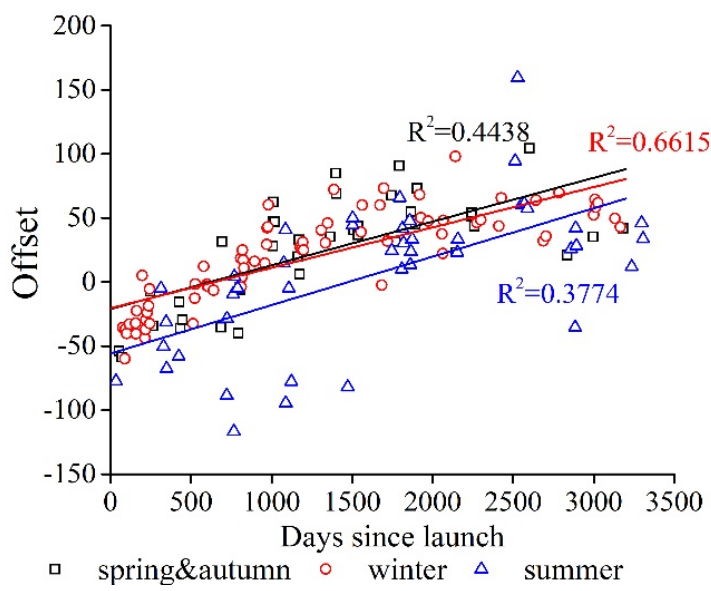

(b)

Figure 13. Changes in radiation calibration coefficients in different seasons. (a) Gain changes in different seasons; (b) offsets changes in different seasons.

\section{Conclusions}

Cross-calibration between the IRS B08 and MODIS B31, B32 was performed using nearsimultaneous image pairs of Lake Qinghai over a 10-year lifetime (2008-2017). All images impacted by cloud or ice were discarded. In addition, since the calibration accuracy decreased significantly when images corresponding to MODIS zenith angles $>50^{\circ}$ were included, those images were excluded as well. The remaining 152 pairs were used to perform radiometric calibration. After various corrections, a very close linear correlation was found between the TOA radiances of IRS B08 and the DNs extracted from HJ-1B IRS images. The cross-calibration coefficients, gains and offsets, were obtained from 2008 to 2017, which compensated for the missing coefficients from 2013 to 2017. The percent difference was within $\pm 4.00 \%$ when compared to the on-board calibrator results. Compared with the field campaign results, the percent difference was within $1.63 \%$. The IRS B08 radiance is lower than that of MODIS B31 and higher than MODIS B32 radiance. However, the TOA temperature between the two sensors are highly consistent with approximately $1 \%$ difference. The calibration coefficients obtained in this study are highly accurate and can thus be used in the radiometric calibration of HJ-1B IRS images. The percent changes of gains were within $\pm 6.5 \%$, although the percent changes of $b$ were more scattered, indicating that the fluctuations of offsets were greater than those of gains. For the same radiance, the corresponding DN varied in different years. The $\mathrm{DN}$ values changed more in the low radiance range but were relatively stable in the normal radiance range. Therefore, the radiance in the normal range of $\mathrm{L}=8.0 \mathrm{~W} \cdot \mathrm{m}^{-2} \cdot \mathrm{sr}^{-1} \cdot \mu \mathrm{m}^{-1}$ was regarded as a fixed point corresponding to $\mathrm{DN}=460$. Combined with another point obtained based on each image, cross-coefficients were calculated. The coefficients manifested different change characteristics in different seasons. The gain and offset values in summer were more volatile than in other seasons, while the winter values were the most stable. As a result, the $\mathrm{DN}$ range of the sensor differed for the same radiance input interval, meaning that the radiometric response of the IRS changed during its orbital lifetime. The response of the IRS decreased from 2008 to 2013 but fluctuated from 2014 to 2017.

With the calibration coefficients provided here, the IRS thermal archive calibrated the radiance to acceptable levels. SST and LST maps can be operationally produced from the IRS radiance data, and these data can also be used in various applications, such as waterline extraction, temperature retrieval and other research areas.

Author Contributions: Conceptualization, W.L. and J.L.; methodology, J.L.; formal analysis, W.L. and Q.C.; validation, Q.H., L.Z. and H.Y.; writing — original draft preparation, W.L.; writing-review and editing, J.L. and Q.C.; funding acquisition, J.L. All authors have read and agreed to the published version of the manuscript. 
Funding: This research was funded by National Key Research and Development Program of China, Grant Number 2018YFB0504903 and Chinese Academy of Sciences Strategic Leading Science and Technology Project, Grant Number XDA19010403.

Acknowledgments: The authors are grateful to the United States Geological Survey (USGS) (https://glovis.usgs. gov/) and the China Center for Resource Satellite Data and Application (CCRSDA) (http://www.cresda.com/CN/) for providing MODIS, Landsat and IRS data.

Conflicts of Interest: The authors declare no conflicts of interest.

\section{References}

1. Du, T.; Yuan, G.; Wang, L.; Sun, X.; Sun, R. Comparison of Remotely Sensed Evapotranspiration Models Over Two Typical Sites in an Arid Riparian Ecosystem of Northwestern China. Remote Sens. 2020, $12,1434$. [CrossRef]

2. Anderson, M.C.; Kustas, W.P. Thermal Remote Sensing of Drought and Evapotranspiration. EOS Trans. 2008, 89, 233-234. [CrossRef]

3. Van Doninck, J.; Peters, J.; De Baets, B.; De Clercq, E.M.; Ducheyne, E.; Verhoest, N.E.C. The potential of multitemporal Aqua and Terra MODIS apparent thermal inertia as a soil moisture indicator. Int. J. Appl. Earth Obs. Geoinf. 2011, 13, 934-941. [CrossRef]

4. Van der Meer, F.; Hecker, C.; van Ruitenbeek, F.; van der Werff, H.; de Wijkerslooth, C.; Wechsler, C. Geologic remote sensing for geothermal exploration: A review. Int. J. Appl. Earth Obs. Geoinf. 2014, 33, 255-269. [CrossRef]

5. Romaguera, M.; Vaughan, R.G.; Ettema, J.; Izquierdo-Verdiguier, E.; Hecker, C.A.; van der Meer, F.D. Detecting geothermal anomalies and evaluating LST geothermal component by combining thermal remote sensing time series and land surface model data. Remote Sens. Environ. 2018, 204, 534-552. [CrossRef]

6. Ninomiya, Y.; Fu, B. Regional Lithological Mapping Using ASTER-TIR Data: Case Study for the Tibetan Plateau and the Surrounding Area. Geosciences 2016, 6, 39. [CrossRef]

7. Ninomiya, Y.; Fu, B. Thermal infrared multispectral remote sensing of lithology and mineralogy based on spectral properties of materials. Ore Geol. Rev. 2019, 108, 54-72. [CrossRef]

8. Tang, H.; Li, Z.L. Quantitative Remote Sensing in Thermal Infrared; Springer: Berlin/Heidelberg, Germany, 2014.

9. Thome, K.; Ara, K.; Hook, S.; Kieffer, H.; Lang, H.; Matsunaga, T.; Ono, A.; Palluconi, F.; Sakuma, H.; Slater, P.; et al. ASTER Preflight and Inflight Calibration and the Validation of Level 2 Products. IEEE Trans. Geosci. Remote Sens. 1998, 36, 1161-1172. [CrossRef]

10. Tonooka, H.; Palluconi, F.D.; Hook, S.J.; Matsunaga, T. Vicarious calibration of ASTER thermal infrared bands. IEEE Trans. Geosci. Remote Sens. 2005, 43, 2733-2746. [CrossRef]

11. Butler, J.J.; Choi, T.; Xiong, J.; Angal, A.; Chander, G.; Xiong, X. Radiometric cross-calibration of the Terra MODIS and Landsat 7 ETM+ using an invariant desert site. In Proceedings of the Earth Observing Systems XIII, San Diego, CA, USA, 11-13 August 2008.

12. Chander, G.; Angal, A.; Choi, T.; Xiong, X. Radiometric Cross-Calibration of EO-1 ALI with L7 ETM+ and Terra MODIS Sensors Using Near-Simultaneous Desert Observations. IEEE J. Sel. Top. Appl. Earth Obs. Remote Sens. 2013, 6, 386-399. [CrossRef]

13. Teillet, P.M.; Markham, B.L.; Irish, R.R. Landsat cross-calibration based on near simultaneous imaging of common ground targets. Remote Sens. Environ. 2006, 102, 264-270. [CrossRef]

14. Xiong, X.; Wenny, B.N.; Wu, A.; Barnes, W.L.; Salomonson, V.V. Aqua MODIS Thermal Emissive Band On-Orbit Calibration, Characterization, and Performance. IEEE Trans. Geosci. Remote Sens. 2009, 47, 803-814. [CrossRef]

15. Vermote, E.F.; Saleous, N.Z. Calibration of NOAA16 AVHRR over a desert site using MODIS data. Remote Sens. Environ. 2006, 105, 214-220. [CrossRef]

16. Li, J.; Gu, X.; Yu, T.; Li, X.; Gao, H.; Liu, L.; Xu, H. A twin-channel difference model for cross-calibration of thermal infrared band. Sci. China Technol. Sci. 2012, 55, 2048-2056. [CrossRef]

17. Wang, Q.; Wu, C.; Li, Q.; Li, J. Chinese HJ-1A/B satellites and data characteristics. Sci. China Earth Sci. 2011, 53, 51-57. [CrossRef]

18. Zhang, C.; Zhou, S.J.; Zhu, L. Three algorithms of sea surface temperature inversion of Daya Bay based on environmental star HJ_1B data. J. East China Inst. Technol. 2013, 36, 88-92. 
19. Zhou, J.; Zhan, W.; Hu, D.; Zhao, X. Improvement of mono-window algorithm for retrieving land surface temperature from HJ-1B satellite data. Chin. Geogr. Sci. 2010, 20, 123-131. [CrossRef]

20. Ouyang, X.; Jia, L.; Pan, Y.; Hu, G. Retrieval of Land Surface Temperature over the Heihe River Basin Using HJ-1B Thermal Infrared Data. Remote Sens. 2014, 7, 300-318. [CrossRef]

21. Man Sing, W.; Jinxin, Y.; Nichol, J.; Qihao, W.; Menenti, M.; Chan, P.W. Modeling of Anthropogenic Heat Flux Using HJ-1B Chinese Small Satellite Image: A Study of Heterogeneous Urbanized Areas in Hong Kong. IEEE Geosci. Remote Sens. Lett. 2015, 12, 1466-1470. [CrossRef]

22. Yang, J.; Gong, P.; Zhou, J.; Huang, H.; Wang, L. Detection of the urban heat island in Beijing using HJ-1B satellite imagery. Sci. China Earth Sci. 2011, 53, 67-73. [CrossRef]

23. Sheng, L.; Lu, D.; Huang, J. Impacts of land-cover types on an urban heat island in Hangzhou, China. Int. J. Remote Sens. 2015, 36, 1584-1603. [CrossRef]

24. Wu, H.; Ye, L.P.; Shi, W.Z.; Clarke, K.C. Assessing the effects of land use spatial structure on urban heat islands using HJ-1B remote sensing imagery in Wuhan, China. Int. J. Appl. Earth Obs. Geoinf. 2014, 32, 67-78. [CrossRef]

25. Lin, L.; Meng, Y.; Yue, A.; Yuan, Y.; Liu, X.; Chen, J.; Zhang, M.; Chen, J. A Spatio-Temporal Model for Forest Fire Detection Using HJ-IRS Satellite Data. Remote Sens. 2016, 8, 403. [CrossRef]

26. Liu, W.; Wang, L.; Zhou, Y.; Wang, S.; Zhu, J.; Wang, F. A comparison of forest fire burned area indices based on HJ satellite data. Nat. Hazards 2015, 81, 971-980. [CrossRef]

27. Ban, Y.; Jacob, A. Object-Based Fusion of Multitemporal Multiangle ENVISAT ASAR and HJ-1B Multispectral Data for Urban Land-Cover Mapping. IEEE Trans. Geosci. Remote Sens. 2013, 51, 1998-2006. [CrossRef]

28. Lu, S.; Wu, B.; Yan, N.; Wang, H. Water body mapping method with HJ-1A/B satellite imagery. Int. J. Appl. Earth Obs. Geoinf. 2011, 13, 428-434. [CrossRef]

29. Barsi, J.A.; Hook, S.J.; Schott, J.R.; Raqueno, N.G.; Markham, B.L. Landsat-5 Thematic Mapper Thermal Band Calibration Update. IEEE Geosci. Remote Sens. Lett. 2007, 4, 552-555. [CrossRef]

30. Wang, Y.; Ientilucci, E. A Practical Approach to Landsat 8 TIRS Stray Light Correction Using Multi-Sensor Measurements. Remote Sens. 2018, 10, 589. [CrossRef]

31. Tonooka, H. Inflight straylight analysis for ASTER thermal infrared bands. IEEE Trans. Geosci. Remote Sens. 2005, 43, 2752-2762. [CrossRef]

32. Chen, G.; Gao, X.; Zhang, S.; Chen, Q.; Tang, L.; Lan, Y. Development of an automatic calibration device for high-accuracy low temperature thermometers. Sci. China Technol. Sci. 2010, 53, 2404-2407. [CrossRef]

33. Wan, Z.; Zhang, Y.; Li, Z.L.; Wanga, R.; Salomonsonb, V.V.; Yvesc, A.; Bossenoc, R.; Hanocq, J.F. Preliminary estimate of calibration of the moderate resolution imaging spectroradioeter thermal infrared data using Lake Titicaca. Remote Sens. Environ. 2002, 80, 497-515. [CrossRef]

34. Xiong, X.; Sun, J.; Barnes, W.; Salomonson, V.; Esposito, J.; Erives, H.; Guenther, B. Multiyear On-Orbit Calibration and Performance of Terra MODIS Thermal Emissive Bands. IEEE Trans. Geosci. Remote Sens. 2008, 46, 1790-1803. [CrossRef]

35. Berk, A.; Andersonb, G.P.; Bernsteina, L.S.; Acharya, P.K.; Dothea, H.; Matthew, M.W.; Adler-Golden, S.M.; Chetwynd, J.H.; Richtsmeiera, S.C.; Pukalib, B.; et al. MODTRAN4 radiative transfer modeling for atmospheric correction. In Proceedings of theOptical Spectroscopic Techniques and Instrumentation for Atmospheric and Space Research III, Denver, CO, USA, 19-21 July 1999.

(C) 2020 by the authors. Licensee MDPI, Basel, Switzerland. This article is an open access article distributed under the terms and conditions of the Creative Commons Attribution (CC BY) license (http://creativecommons.org/licenses/by/4.0/). 